\title{
Auto-Audit of Digital Earth and Beyond
}

\author{
Yuri Baturin*1 \\ ${ }^{1}$ Lomonosov Moscow State University, Moscow, Russia, itlaw@audit.msu.ru
}

\begin{abstract}
The question is posed: "If we use the Digital Earth to verify the results of an audit (e.g. land cadastre) conducted in a traditional format, who can verify the Digital Earth itself?" The answer is, "The Digital Earth can audit itself. Only you have to teach it to do it". The mechanism of self-checking is proposed to be realized through autoreflexion. If Digital Earth is "taught" autoreflexion, there are no obstacles to the transition to peer-to-peer reflexion and multirange reflexion. The reflexive model of the Digital Earth is discussed both in the case of ordinary introspection (auto-audit) and in the case of multiple ranks of reflexion. The way of inclusion of the person in the digital network as a support structure of the Digital Earth is discussed. At the next level of development the reflexive Digital Earth becomes recursive, which means development toward the noosphere as understood by academician Vladimir I. Vernadsky - the thinking Digital Earth. Finally, at the highest stage of development Digital Earth will understand man and humanity.
\end{abstract}

\section{Keywords}

Digital Earth, Auto-Audit, reflexion, noosphere.

\section{Introduction}

Let me to start with a quote from a philosopher. Josiah Royce in his book "The World and the Individual" formulated the following: "Let's imagine that a part of the land of England has perfectly aligned, and on it the cartographer circles the map of England. The work is perfect; there are no details about the land of England, even if they are minute, that are not marked on the map; everything has its correspondence there. This map in such a case must contain a map of the map, which must contain a map of the map of the map, and so on ad infinitum ." ${ }^{1}$ This is nothing more than introspection or self-reflexion: the country looks into itself through its precise map.

Let's extend the thought experiment. A Professor at "Sylvie and Bruno" by Lewis Carroll talked about creating a 1:1 scale map of the country. ${ }^{2}$

Al Gore replaced the map with a globe and came up with a Digital Earth. ${ }^{3}$

Digital Earth is a set of objects digitized and presented in accordance with the principles of neogeography.

\footnotetext{
Corresponding author

1 Royce J (1900) The World and the Individual. First Series. "The Four Historical Conceptions of Being". New York: Macmillan, p.505.

2 Carroll L Sylvie and Bruno. - In: The Complete Illustrated Lewis Carroll. Wordsworth Editions Ltd. Cumberland House, Hertfordshire, 1996. p.556.

3 Gore A (1992) Earth in the balance: ecology and the human spirit. Houghton Mifflin Harcourt Publishing, Boston.
} 


\section{Discussion}

So we moved from cartography to neogeography, including Digital Earth, which is exactly what we are looking for. Let's continue our thought experiment and imagine a similar process not on the map, but on the whole Earth, on the Digital Earth. Any digital fragment contains the same fragment at a different scale, which in turn contains a fragment at a different scale. This is a mechanism for implementing the scale-independed nature of the Digital Earth.

What are the next steps in the development of the Digital Earth? It seems to me, that we should strive for a Reflexive Digital Earth, that is, a Digital Earth that learn about itself.

This stage requires several steps.

Firstly, for this purpose it is necessary to include the reflexive Digital Earth in the topology of the world wide web. The Internet space is not only a complex technical object, but also a community of persons who enter into various connections with each other and various relationships about the information circulating in the world's infrastructure. Therefore, we must include human beings in the Digital Earth. How do we do this? How is the technical network of the Internet connected to the community (network) of persons where, in fact, a large part of life on Digital Earth unfolds?

So, there is an Internet space as a complex technical object, as a network of technical devices. At each node of the technical network a person appears (or can appear). This means that we can talk about a kind of social network, or rather a set of realizations of a common social network, corresponding to the technical structure of the Internet. Nodes are human inner worlds, but the meaning of the Internet is hidden not in the nodes, but in the connections between them, that is, in the relations between the members of the emerged community. Through the established connections, new content is induced in other nodes of the network. In fact, over the technical part of the network defined by physical connections and connection points (nodes), a second - field (induced) network of connections emerges, describing the circulation of ideas, discussions, finally, public opinion, which defines the community. But how do these two networks create unity? As long as the technical network (the Internet) is not induced (not excited by human informational influence), it is only a physical circuit. The induced network is the human essence of the Internet. Thus, nodes are connected not only by physical connections, but also by "force lines" of the induced field. And once the relationship between the "nodes" has arisen, it requires social regulation. In this sense, Digital Earth, as a space "stretched" on the Internet becomes not only a technical, but also a 
social phenomenon. The technical Internet network induces a social network of thinking elements of the Digital Earth.

So, the Internet as a support structure of the Digital Earth is a dual system, the physical subsystem of which is a set of loops and node pairs. Analysis of the physical subsystem of the Internet, for example, in order to establish the optimal routing is done by methods of graph theory. Mathematically, we can incorporate the social network into the Digital Earth through a graph theory model, translating the graph of the technical network into the graph of representations that each of its elements has. Analysis of the field (induced) subsystem of the Internet, which describes the circulation of information and collective generation of content, as much more complex, requires the use of tensor analysis. The field subsystem can be described by equations like Ohm's law and Kirchhoff's law for electric circuits or by thermodynamic analogies, for example by introducing information potentials. It is possible to look at the Digital Earth in a different way, through a complex structure of configuration Internet space, its stratifications (Tor Browser, Dark Net), through deep floors of the Internet space - different kinds of online universes (worlds), etc. But that's another topic.

About 10 years ago, at the Institute for the history of natural science and technology of the Russian Academy of Sciences, we implemented a digital globe where we demonstrated 3Ddocuments with a coordinate reference and Internet connection to get real-time information. ${ }^{4}$ (The concept 3D-document was introduced by Diter Fellner in 2007. ${ }^{5}$ It has proved extremely useful for the Digital Earth). We transferred this technology to the Geophysical center of the Russian Academy of Sciences, where they successfully developed it.

Lets go to the next steps.

Each of us has self-awareness. But to understand who we are, what humanity is, we as a community must have self-awareness. This procedure - self-discovery (auto-audit) of humanity, that is, the interpretation of many random external signals that tell us who we are, can be carried out by starting from the Digital Earth. In addition to introspection, this will also allow us to interpret reality.

If we use the Digital Earth to check the results of an audit (e.g., a land cadastre) conducted in a traditional format, who can check the Digital Earth itself? The answer is simple: the Digital Earth

\footnotetext{
Baturin YuM Modelling As a Backup Tool for the History of Science and Technology. - Herald of the Russian Academy of Sciences, 2013, vol.83, No.1, pp.1-7.

5 Fellner DW, Saupe D, Krottmaier H Guest Editors' Introduction: 3D Documents. IEEE Computer Graphics and Applications, vol. 27, no. 4, July-Aug. 2007, pp. 20-21.
} 
can check itself. But we have to teach it to do this. An attempt can be made to implement the selftest mechanism through autoreflexion. In fact, it is necessary to introduce a feedback mechanism, a kind of "mirror" by means of which the Digital Earth, as a global phenomenon, can check and, therefore, correct itself (auto-audit).

If Digital Earth is "taught" autoreflexion, there are no obstacles to the transition to peer-topeer reflexion and multirange reflexion, which means that it becomes a potential interlocutor. Hypothetically such an interlocutor could be an extraterrestrial mind, but we will not discuss this version as irrelevant for now.

So, we got a Reflexive Digital Earth. In other words, Digital Earth will contain a model of the Digital Earth, with which it interacts, realizing itself, talking to itself. It will already be a reflexive Digital Earth.

What's next? We can set the task of increasing the ranks of reflection. That is, create a recursive Digital Earth. And this means moving towards the emergence of the noosphere, as it was understood by academician Vladimir I. Vernadsky.

Finally, the next step is to move away from the traditional coordinate systems used in cartography and GIS to p-adic coordinate systems as more appropriate to human thinking. ${ }^{6}$ With the appearance of Descartes' coordinate system, a numerical image of physical space was actually created. However, a lot of efforts and time were still needed to create an accurate mathematical model to digitize physical space. It was necessary to create a mathematical structure in which the process of reducing the size of the Cartesian lattice could go on to infinity, guaranteeing in the limit the infinite accuracy of the digital representation of material objects. The corresponding mathematical structure is now known as the field of real numbers. But to describe the mind, the thinking Digital Earth will need to move from real numbers and traditional digitization to p-adic numbers and corresponding tree-like coordinate system, which entails a fundamentally different digitization (another very specific way of information coding). It is necessary to move from traditional digitization to coding based on p-adic numbers. It is in this direction that we see a real way to model human thinking and create artificial intelligence. A "re-digitized" and therefore altered Digital Earth will be able to understand humans and humanity. Perhaps this will be the Earth with a noosphere according to academician Vernadsky, at least one of its interpretations.

6 Khrennikov A.Yu. p-adic information spaces, infinitely small probabilities and anomalous phenomena. - Journal of Scientific Exploration, 1999, vol.4, \# 13, p.665-680. 


\section{Conclusions}

Thus, we will gradually get:

- a reflecting, self-aware Digital Earth (auto-audit of Digital Earth)

- a Digital Earth with an increasingly high rank of reflection (this is the path to the noosphere)

- a Digital Earth that understands a person and humankind.

Digital Earth must become the interlocutor of humanity. This task is practically essential to the survival and preservation of humans as an Earth species.

Digital Earth is rapidly evolving, as is its configuration space, the "receptacle" of this phenomenon itself, a well-visualized network (many are familiar with picture-charts of this kind) stretched over many reference points located all over the planet and even in near-Earth (so far) outer space. Humanity cautiously enters new nooks of Digital Earth that are opening up and starts mastering them. But the new subspaces of the Digital Earth pose many practical questions for scientists, which are not easy to solve. But they at least need to be formulated and posed.

\section{References}

Baturin YuM (2013) Modelling As a Backup Tool for the History of Science and Technology. - Herald of the Russian Academy of Sciences, vol.83, N 1, pp.1-7

Carroll L (1889) Sylvie and Bruno. - In: The Complete Illustrated Lewis Carroll. Wordsworth Editions Ltd. Cumberland House, Hertfordshire, 1996, p.556

Fellner DW, Saupe D, Krottmaier H (2007) Guest Editors' Introduction: 3D Documents. IEEE Computer Graphics and Applications, vol. 27, N 4, July-Aug, pp. 20-21

Gore A (1992) Earth in the balance: ecology and the human spirit. Houghton Mifflin Harcourt Publishing, Boston.

Khrennikov AYu (1999) p-adic information spaces, infinitely small probabilities and anomalous phenomena. - Journal of Scientific Exploration, vol.4, N 13, pp. 665-680

Royce J (1900) The World and the Individual. First Series. "The Four Historical Conceptions of Being”. New York: Macmillan. - p. 588 